\title{
Voltammetric Characterization Methods for the PEM Evaluation of Catalysts
}

Shawn Gouws

Additional information is available at the end of the chapter

http://dx.doi.org/10.5772/47248

\section{Introduction}

\subsection{Electrolytic units}

Electrolysis is a chemical reaction that produces electrical energy via an electrochemical process. This electrical energy is the driving force needed for the chemical reactions. This phenomenon was first observed by Nicolson and Carlisle in 1789. Hydrogen is considered to be one of the most promising energy carriers for providing clean, reliable and sustainable energy systems (Balaji et al., 2011). It could be beneficial in meeting the global threat of climate change; and it could eliminate those issues associated with the use of fossil fuels. Although the production of hydrogen is more expensive than fossil fuel, it is an inexhaustible resource that could meet most of our future energy needs (Van Ruijven et al., 2007)

During the process of water electrolysis, the water molecule is decomposed into hydrogen and oxygen when an electric current is passed through the system. Electrical current causes positively charged ions to migrate to the negatively charged cathode, where the reduction takes place in order to produce hydrogen gas (Zoulias et al. 2004,).

At the other electrode - the anode - oxygen is produced and escapes as a gas. The stoichiometry of the chemical reaction is that two molecules of hydrogen are produced for every one molecule of oxygen formed.

$$
\begin{aligned}
& \text { Anode reaction: } 2 \mathrm{H}_{2} \mathrm{O} \rightarrow 4 \mathrm{H}^{+}+4 \mathrm{e}^{-}+\mathrm{O}_{2} \\
& \text { Cathode reaction: } 4 \mathrm{H}^{+}+4 \mathrm{e}^{-} \rightarrow 2 \mathrm{H}_{2} \\
& \text { Overall reaction: } 2 \mathrm{H}_{2} \mathrm{O} \rightarrow 2 \mathrm{H}_{2}+\mathrm{O}_{2}
\end{aligned}
$$


Electrolysis is considered to be one of the cleanest methods of producing hydrogen (Qi, 2008). The following section introduces briefly different kinds of electrolytic units that are currently being used to generate hydrogen for use in PEM fuel cells. There are two possible methods of interest for producing pure hydrogen on a large scale. The first method of interest is the alkaline electrolytic units that are currently being used in industry to generate hydrogen. The reason for the use of alkaline electrolysis is that it is easier to control the corrosion effects compared with acid-based electrolysis technologies, such as the phosphoric acid electrolyser. Another method, and one of more interest, is the proton exchange membrane (PEM) electrolyser that has been developed (Atlam \& Kolhe 2011) over recent years.

These PEM electrolytic units are less corrosive than the alkaline electrolytic medium that uses large quantities of caustic soda. Another advantage is that due to the membrane used in PEM electrolysers, the explosion rate between hydrogen and oxygen is at a minimum compared with that in alkaline electrolysers. Another advantage to PEM electrolysers over traditional technologies are there higher production rates and more compact design (PSOF\&U, 2008, p66).

Because of oxygen and hydrogen generated in the electrolytic unit, and the subsequent high pressures generated, safety procedures are required for the storing and disposal of the large amounts of potassium hydroxide. Currently, the fields of application of PEM electrolysers at different capacities have been widening over the spectrum of applications. PEM electrolyser are utilized not only for the production of hydrogen from PEM fuel cells, but they can also be used for online hydrogen production to analytical laboratories (equipment such as gas chromatography, hydrogen supply for laboratory usage), hydrogen welding, metallurgy of specially pure metals and alloys, as well as the production of pure substances for the electronic industry.

In terms of economic limitations, PEM water electrolysis remains an expensive technology; and further research and development need to be done to reduce the noble metal content in a PEM water electrolyser (Millet et al., 2011). This could open a commercial route for the domestic usage of PEM electrolyser units. PGM metals - in particular Pt and Ir metal oxides - are still being widely used in this highly acidic environment found in perfluorinated proton-conducting materials used in the manufacture of the membrane electrode assembly (MEA).

One possibility for reducing PGM costs in a PEM electrolyser unit, is to reduce the catalytic content on the MEA to as low as $0.3-0.5 \mathrm{mg} \mathrm{cm}^{-2}$. This can be achieved by depositing Pt nano-particles on the surface of carbon carriers of large surface areas (Millet et al., 2011). It must be noted that the cost is not only due the noble metal, but also in their precursor salt costs that are used in the initial plating process.

The focus of this chapter will be on the characterization and feasibility of PEM electrolyser catalysts used in the anode and cathode compartment. In order to achieve this characterization, it will be necessary to discuss cyclic voltammetry, kinetic aspects such as 
the comparison of Tafel slopes determined from the electrolyser I-V curves, in addition to thermodynamic studies to determine the hydrogen efficiencies.

\subsubsection{Alkaline electrolysers}

The theory of alkaline water electrolysis is illustrated in Figure 1 in the example of a monopolar arrangement electrolyser. Two molecules of water are reduced to one molecule of hydrogen and two hydroxyl ions at the cathode. The hydrogen ions escape from the cathode and recombine to produce gaseous hydrogen. The hydroxyl ions migrate between the anode and cathode compartments through a porous diaphragm (Zoulias et al., 2004).

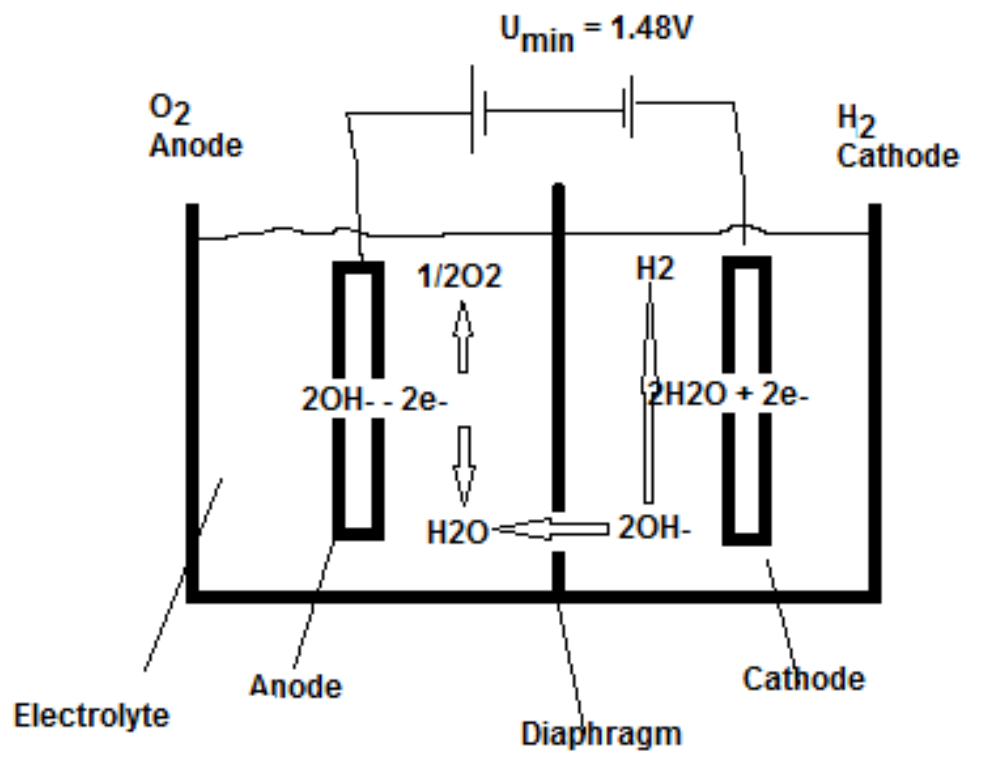

Figure 1. Alkaline electrolysis (Kreuter and Hofmann, 1998)

Half of a molecule of oxygen escapes at the anode surface; then it recombines and leaves the system as a gas. Some of the advantages of alkaline electrolysers are that the construction materials and electrolytes are relatively cheap in comparison with those required in acid electrolytic technologies. The current densities to operate these systems are relatively low; and consequently, they are economically feasible. However, these types of water electrolysers do have several disadvantages

These alkaline electrolysers are limited in their ability to be constructed into multiple cell configurations that have typically low current densities. These types of electrolysers need to be purged with an inert gas, such as nitrogen or argon, to prevent the system reaching explosive limits between the oxygen and the hydrogen

Alkaline electrolysers also utilize large concentrations of potassium hydroxide, which is a very corrosive material - especially at elevated temperatures. 


\subsubsection{Proton-exchange membrane electrolyser}

The proton-exchange membrane electrolyser is based on the use of a polymeric proton exchange membrane as the solid electrolyte that can produce carbon-free hydrogen from water electrolysis (Marshall et al., 2007). The first PEM was introduced by General Electric for fuel cell application - and later for electrolyser application (Millet et al., 1996). PEM electrolyser systems offer numerous advantages over other types of electrolyser technologies. These advantages include greater energy efficiency, higher production rates, and more compact design (Oberlin \& Fisher, 1996). A schematic representation of a PEM electrolysis cell is shown in Figure 2.

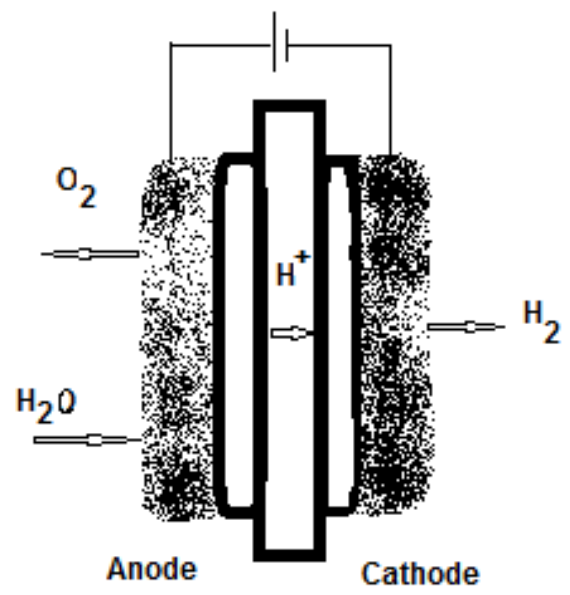

Membrane

Figure 2. PEM water electrolyser

The PEM electrolyser consists of a membrane electrode assembly (MEA) to which an anode and a cathode are bonded. Typical catalyst particles for the anode utilization could be $\mathrm{Pt}$, $\mathrm{IrO}_{2}$, or mixtures, such as $\mathrm{Ir}_{x} \mathrm{Sn}_{1-x} \mathrm{O}_{2}$ (Marshall, 2004, 2005). The normal catalyst particles utilized for the cathode could be, for example, Pt. The electrical contact and mechanical support are established by means of porous metallic meshes. Hydrogen is produced in a PEM electrolyser by supplying water to the anode, where it splits into oxygen, hydrogen ions and electrons. The hydrogen ions migrate through the MEA to the cathode, where the protons and electrons re-combine to produce hydrogen gas.

Anode: $\mathrm{H}_{2} \mathrm{O} \rightarrow 4 \mathrm{H}^{+}+\mathrm{O}_{2}+4 \mathrm{e}^{-}$

Cathode: $2 \mathrm{H}_{2} \mathrm{O}+4 \mathrm{e}^{-} \rightarrow 2 \mathrm{H}_{2}$

Overall cell: $2 \mathrm{H}_{2} \mathrm{O} \rightarrow 2 \mathrm{H}_{2}+\mathrm{O}_{2}$ 
The first PEM water electrolyser was installed in 1987 at Stellram, SA, a metallurgical specialty company, in Nyon, Switzerland. This unit was designed to produce up to $20 \mathrm{Nm}^{3} \mathrm{~h}$ ${ }^{1}$ of hydrogen at a pressure of 1-2 bars. The second designed PEM water electrolyser was demonstrated at Solar Wasserstoff Bayern (SWB); and it was slightly different from the first design used at the Stellram plant. The main difference was that the thickness of the bipolar plates was reduced. The stacks consisted of 3 modules of 40 cells each (Zoulias et al., 2004). Presently, the use of PEM electrolysers produced by Proton, are only sized for the home or small electrical grid systems.

The high capital costs of PEM electrolysis units has resulted in their limited viability in the large hydrogen production market, when compared to alkaline electrolysis systems, with their lower capital costs, producing a range of hydrogen capabilities (Ivy, 2004 and PSOF\&U 2008).

However, the development of PEM electrolyser systems has been slow, due to the cost of components, such as the precious metals used as electrocatalysts. Currently, there is still no non-noble metal that could be used as an electrocatalyst with satisfactory results. It is of great importance to reduce the noble metal content in the development of catalysts for PEM water electrolysers. Most of the overpotential losses that occur happen at the anode electrode, where oxidation takes place. Because of the acidic environment and high anode potential during water electrolysis, non-metal catalysts, lke $\mathrm{Ni}$ and $\mathrm{Co}$, cannot be used because of corrosion (Millet, 1994).

High overpotentials for the oxygen evolution reaction (OER) were experienced for $\mathrm{Pt}$ electrocatalyst, making a Pt catalyst a poorly conducting oxide. Other possible noble metal catalysts, such as Ir or Ru, make very good conductors. However, Ru is unstable and needs to be used with other catalysts, such as $\mathrm{IrO}_{2}$ for example.

Tseung and Jasem (Tseung and Jasem, 1977) and Trasatti (Trasatti, 1991) give good guidelines for the choice of oxide electrocatalysts needed for OER. The OER can only proceed when the electrode potential is higher than the potential of the metal/metal oxide couple, or the lower metal oxide/higher metal oxide couple, which indicates that the OER is governed by the surface electrochemistry (Song et al., 2008). The membrane material for the PEM electrolyser unit is Nafion ${ }^{\mathrm{TM}} 117$, and this is manufactured by DuPont.

Individual cells can be stacked in bipolar modules with graphite separator plates that would provide the manifold for the water feed and the gas evacuation.

\section{Cyclic voltammetry}

All electrochemical techniques involve the use of electricity as either an input or an output signal. The function of an electrochemical instrument is to generate an input electrical signal as a function of time, and to measure the corresponding output signal as a function of either the voltage, current or charge (Qi, 2008). Charge is the integration of current with time. The input electrical signal is generated by an electrochemical reaction at the working electrode 
and the counter electrodes. This can be illustrated in Figure 3 for a typical CV waveform produced. When the voltage is swept past a potential corresponding to an active electrochemical reaction, the initial forward scan for the current will give a spiked response, which will consume the electrons involved in that reaction. On the reverse voltage scan, the reverse electrochemical reaction will be observed. The shape and size of the peaks give information about the relative kinetic rates and diffusion coefficiencies of the electrochemical system.



(a)

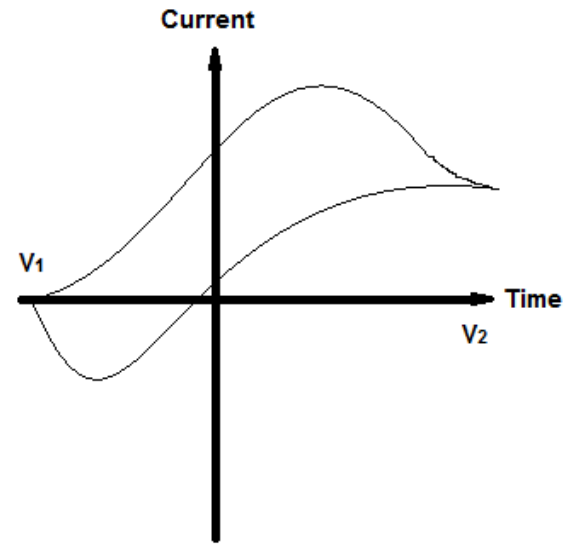

(b)

Figure 3. Schematic representation of a CV waveform and typical resulting current response (a). In a $\mathrm{CV}$ experiment, the voltage is swept linearly back and forth between two voltage limits $\left[\mathrm{V}_{1}\right.$ and $\left.\mathrm{V}_{2}\right](\mathrm{b})$. The resulting current is plotted as a function of voltage.

\subsection{Volumetric studies}

During the electrolysis of water, hydrogen and oxygen are produced at the surface of the polymer electrode membrane. These catalyst layers on the membrane need voltammetric characterization. The most important techniques used in electrochemical characterization include potential cycling, potential sweep, and rotating disk electrodes.

An electrochemical reaction step consists of at least one of the following steps: the transport of the reactants to the surface of the electrode, and adsorption of the reactants onto the surface of the electrodes. Charge transfer occurs through either oxidation or reduction on the surface of the electrode, and the transporting of product(s) from the surface of the electrode follows. The purpose would be to characterize each of these steps that are taking place inside a PEM electrolysis cell (Qi, 2008).

The cyclic voltammetry technique is one of the most commonly used techniques in electrochemical analysis for the study of electro-active catalytical species and electrode surfaces (Kumpulainen et al., 2002). 
The characterization of the electrochemically active species would be carried out in a typical three-electrochemical cell. These are typically: a conventional 3-electrode cell, a half cell and single cell. In these types of cells, the catalysts and the electrodes will be characterized in the form of the working electrode, the potential of which, or the current, will be monitored or controlled in a specific environment.

What happens on the surface of the working electrode will comprise the heart of the investigation. The second electrode is called the counter electrode in the circuit; and the current flowing through the circuit would cause a reaction on the counter electrode as well. However, the investigation has no interest in what happens on the counter electrode surfaces, so long as it does not interfere with the working of the electrode (Qi, 2008)

In order to minimize the impact of the electrolyte resistance to the potential of the working electrode, a third electrode is introduced - called the reference electrode. This is often used to form a second circuit with the working electrode. Ideally, this electrode should be nonpolarizable and should maintain a stable potential. There is high impedance in the voltage measurement equipment, which makes the current in the circuit very small (Qi, 2008).

A typical 3-electrode cell is shown in Figure 4, where the working electrode is the exposed area of a glassy carbon electrode impregnated with the catalytic material being tested. A piece of Pt wire - in the form of a coil or sheet - could be used as the counter electrode. The reason for a large surface counter electrode is to ensure that the electrochemical reaction occurring is large enough so that there is no interference with the performance of the working electrode. The reference electrodes used are typically electrodes, such as $\mathrm{Pt} / \mathrm{H}_{2} / \mathrm{H}^{+}$ (standard or dynamic hydrogen electrode), $\mathrm{Ag} / \mathrm{AgCl} / \mathrm{Cl}^{-}$(silver/silver chloride) and $\mathrm{Hg} / \mathrm{Hg}_{2} \mathrm{Cl} / \mathrm{Cl}^{-}$(the calomel electrode).

When the counter electrode might possibly interfere, it is often placed in a separate compartment - away from the working electrode - to ensure that there is no interference. This is done by placing the counter electrode in a porous frit, such as a sintered porous glass or an electrolyte bridge.

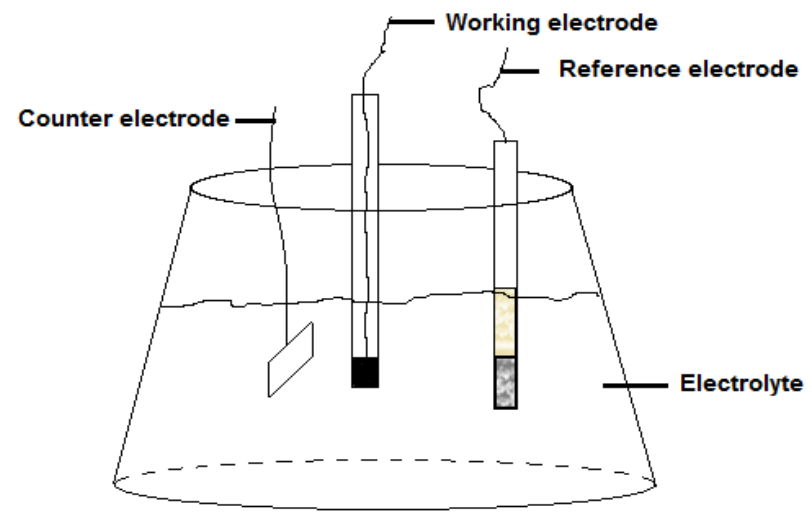

Figure 4. This demonstrates the basic setup of a conventional 3-electrode cell 
This conventional 3-electrode cell was used to characterize the half-cell reactions of the catalyst that would occur on either side of the PEM electrolyser cell.

\subsection{The basic principles of CV studies}

The initial working potential is usually set at a potential that does not cause any electrochemical reaction. After the CV scan is started, the potential is either increased to a maximum, or decreased to a minimum, indicating either an oxidation or reduction reaction of an electrochemically active species; and then an anodic (or cathodic) current appears. The current response, as a result of this polarization, is then plotted as a function of the applied potential. The current voltage curve is referred to as the cyclic voltammogram; and it gives information about the electrochemical reactions taking place on the working electrode surface (Kumpulainen et al., 2002).

Other information regarding the adsorption and desorption of hydrogen could also be obtained.

As the kinetics of the reaction go faster, there will be an increase or decrease in the anodic (or cathodic) currents. The maximum is reached when all the electrochemically active species oxidized or reduced have been consumed in the electrochemical reaction. The highest current in Figure 5(b) is achieved at the moment that the mass transfer rate is at its maximum. This is driven between the gradient of the bulk concentration of the electrochemically active species and that of the surface concentration on the working electrode area.

When the potential increases beyond this point, the current starts to decrease due to the double layer thickness increases, resulting in a less-steep concentration gradient of the active species. When the potential reaches the set high or low potential, the scan is reversed, forming thereby a cyclic voltammogram.

The concentration gradients are linear, and the ratio of oxidized to reduce species for a reversible reaction, is given by the Nerst equation (Eqn. 1)

$$
E_{e}=E_{e}^{o}+\frac{R T}{n F} \ln \frac{C_{O}}{C_{R}}
$$

Where $E_{e}$ is the equilibrium potential $(\mathrm{V})$ and $\mathrm{Ee}^{\mathrm{o}}$ is the standard potential $(\mathrm{V}) . \mathrm{R}, \mathrm{T}, \mathrm{n}$ and $\mathrm{F}$ are constants and $C_{0}$ and $C_{R}$ the surface concentrations of the oxidized and reduced species. When the scan rates are increased, this shortens the timescale of the CV redox cycle and the concentration gradient has time to relax. This relationship between the peak current density and the scan rate is mathematically shown by the Randles-Sevcik equation (Eqn.2) (Heineman and Kissinger, 1996):

$$
\mathrm{I}_{\mathrm{p}}=\left(2.69 \times 10^{5}\right) \mathrm{n}^{3 / 2} \mathrm{AD}^{1 / 2} \mathrm{C}^{\mathrm{o}} \mathrm{v}^{1 / 2 \mathrm{a}}
$$

At $25^{\circ} \mathrm{C}$ where $\mathrm{i}_{\mathrm{p}}$ is the peak current $(\mathrm{A}) ; \mathrm{n}$ is the number of electrons transferred; $\mathrm{A}$ is the electrode area $\left(\mathrm{cm}^{2}\right)$; $\mathrm{D}$ is the diffusion coefficient of the species being oxidized/or reduced $\left(\mathrm{cm}^{2} / \mathrm{s}\right) ; \mathrm{C}^{0}$ is the concentration of this same species in the bulk solution $\left(\mathrm{mol} \mathrm{cm}^{-3}\right)$; and $v$ is the scan rate $(\mathrm{V} / \mathrm{s})$. There should be a linear relationship between the peak current density 
and the square root of the scan rate. Any deviation from this relationship can be related to a quasi-reversible or completely irreversible system.

In search of redox couples, the electrode potential sweeps rapidly (meaning moving back and forth). The characteristics of the reversible electrochemical reaction on CV record are as follows (Eqn. $3-4)$ :

$$
\begin{gathered}
\Delta \mathrm{E}=\mathrm{E}_{\mathrm{p}^{\mathrm{a}}}-\mathrm{E}_{\mathrm{p}^{\mathrm{c}}}=59 / \mathrm{nmV} \\
\mathrm{I} \mathrm{i}_{\mathrm{p}^{\mathrm{a}}} / \mathrm{i}_{\mathrm{p}} \mathrm{I}=1 \\
I_{p} \propto \mathrm{V}
\end{gathered}
$$

According to Eqn. 2, Ip is proportional to $v^{1 / 2}$. Although the peak currents increase with scan rate, the potential at which the peak occurs is invariant with scan rate. This is shown in Eqn. 4.

\section{Preparation of the working electrode surface}

Noble metal catalysts were prepared by reducing the chloride precursor by means of a fusion process, called the Adam's method (Adam \& Shriner, 1923) with a solution of sodium nitrate, to produce $\mathrm{M}\left(\mathrm{NO}_{3}\right)$. This is then annealed at $340^{\circ} \mathrm{C}$ - to produce the metal oxide (Cheng, 2009 \& Marshall, 2007). This method has been used successfully for the preparation of several anode catalysts in PEM water electrolytic systems (Hutchings et al., 1984); and it was found to be convenient and fast for the screening of different catalysts.

For example a reaction can be written as follows:

$$
\begin{gathered}
6 \mathrm{NaNO}_{3}+\mathrm{H}_{2} \mathrm{IrCl}_{6} \rightarrow 6 \mathrm{NaCl}+\operatorname{Ir}\left(\mathrm{NO}_{3}\right)_{4} 2 \mathrm{HNO}_{3} \\
\operatorname{Ir}\left(\mathrm{NO}_{3}\right)_{4} \rightarrow \mathrm{IrO}_{2}+4 \mathrm{NO}_{2}+\mathrm{O}_{2}
\end{gathered}
$$

A typical method would be to charge a reactor with the metal precursor; and then to mix the precursor thoroughly with sodium nitrate mixed previously in water. After mixing, the water is evaporated; and the remaining slurry is heated to $340^{\circ} \mathrm{C}$ to produce the crude Iridium Oxide. This product is washed to remove the salts produced in the reaction, then dried and stored to be used in characterization and evaluation (Rasten et al., 2003).

For PEM electrolyser cell applications, the catalysts need to be annealed to the surface of a glass carbon electrode, in order to be used to screen various catalyst mixtures, or to study the reaction mechanisms and kinetics by coating the electrode with a layer of catalysts. A catalyst is first thoroughly mixed with other components, such as short-chain alcohols, for example water, ethanol, or isopropanol - through agitation and/or sonication. Other solvents such as 1, 2 propanediol may be added, in order to create a formulation that can assist the catalyst to disperse to the glass carbon surface.

Sonication and agitation can increase the temperature of the catalyst mixture, in order to make the mixture more viscose, and thereby to increase the dispersion onto the working 
electrode. The catalyst formula is then applied to the working electrode surface and dried. In order to ensure that the catalysts particles adhere to the surface of the working electrode, it is important to add convenient additives, such as a perfluorinated isomer like DuPont's or Dow's Nafion. A second ultrathin layer could be applied on the top of the catalyst layer to enhance adhesion. It is important to dry the catalyst layer above the glass transition temperature stage of the Nafion ionomer, so that it can adhere effectively. The surface of the electrode disk itself should be inactive to the electrochemical reaction.

For example, if the catalyst particles are platinum, the surface cannot be platinum as well. This is done by ensuring that the metal used on the surface is not the same as the metal under investigation.

\section{The selection of the electrolyte}

A dilute aqueous acid solution, for example a $0.1-1 \mathrm{M}$ solution, is typically used as the electrolyte. The reason for this is that there is an exchange of protons between the various reactions taking place inside the electrolytic cell. Sulphuric acid has been use extensively for these types of studies, and it resembles a typical solid electrolyte used in the membrane electrode assembly (MEA) of the PEM electrolyser. However, sulphate anions can adsorb on the surface of Pt catalysts, which alters the reaction kinetics of the cell. Instead, perchloric acid can be used as an electrolyte medium, which does adsorb onto the surface of the $\mathrm{Pt}$ catalyst.

\section{What do we need to characterize for a PEM electrolyser cell to be most effective?}

In this section, the various PEM electrolyser properties are listed that may need characterization:

- $\quad$ Overall performance of electrolyser (J-V curves)

- Kinetic properties (electrochemically active surface)

- Ohmic properties (electrolyte conductivity, contact residence, electrode resistance)

- Mass transport properties (pressure losses, reactant/ product homogeneity)

- Catalytic structure (catalyst loading, particle size, electrochemically active surface area)

This list gives an idea of the different kinds of properties that can be used to characterize PEM electrolyser catalysts that could contribute to the overall performance and behaviour of electrolysis. How do we know on what property to focus, or which one is important to characterize? In this chapter, the focus will be on just a few of the most widely used characterization techniques, such as for example, cyclic voltammetry, linear potentiometer and rotating disc electrode techniques.

Let us start with basic electrochemical techniques to characterize the catalysts for PEM electrolysers. These could provide quantitative information about the performance of PEM electrolysers. 
There are two types of electrolyser characterization:

a. Electrochemical characterization techniques (in situ). These techniques use variables that measure various electrochemical properties, such as potential, current and time required to characterize the catalytic behaviour.

b. Ex situ characterization techniques. These techniques characterize the detail of the structural properties of the catalyst.

With respect to the first type of the PEM electrolyser characterization, I will discuss three major techniques:

1. Cyclic voltammetry (CV). This is a sophisticated technique that provides valuable information on the kinetics of the PEM electrolyser reactions. CV in general can be time consuming, and some of the results might be difficult to interpret. This can be overcome by specialised modified methods under argon or nitrogen.

2. Current - Voltage $(J-V)$ measurement. The most needed PEM electrolysis technique is a J-V measurement that provides an overall quantitative evaluation of a PEM electrolyser's performance. The J-V curves shows that, depending on different types of electrolyser, where the current starts to flow would indicate where hydrogen gas starts to be released from the electrolyser unit. This galvanic cell has a certain polarization voltage which will set off the current. A further increase in the external voltage indicates the ongoing development of the gas. The minimum voltage at which the splitting of water begins is called the decomposition voltage. For PEM electrolysers, this voltage is $1.23 \mathrm{~V}$. The main difference between the theoretical and the experimental voltage could be the overpotential. The overpotential is a function of the electrode material, the texture of the electrode surface, the type and concentration of the electrolyte, the current density and the temperature. In practical applications, it is the aim to minimize the overpotential. This is important, in order to achieve a very good and active electrode surface.

3. Demonstrating hydrogen efficiency - To ensure that the PEM electrolyser performs correctly, it would be advantageous to measure the hydrogen efficiency in the electrolyser cell.

In the area of ex situ characterization, one can discuss the following methods:

1. Porosity determination is an effective characterization method, due to the high porosity that the catalyst structure must have, in order to be a good and effective catalyst for PEM electrolysers.

2. Surface area measurements could be achieved by either the Brunauer-Emmett-Teller (BET) analysis, or by means of XRD to determine the catalysis particle size; this, in turn, can be related to the electrochemically active surface area measurements.

3. Gas permeability: Even if the electrodes are highly porous, it does not mean that the gas will necessarily permeate through the membrane. Therefore, understanding mass transport in PEM electrolyser electrodes requires permeability measurements, in addition to porosity measurements. Gas permeability testing is an important factor in the development of ultra-thin membranes. 
4. Chemical determination can assist in the physical characterization of the materials used in the PEM electrolyser cell.

\section{Electrochemically active surface area}

An electrochemically active surface area (ECSA) (Eqn 5) can be determined from the scanning of a cyclic voltammetry. This is needed in catalyst characterization, in order to obtain critical data regarding the surface activity of the catalysts. This technique for the determination of ECSA for PEM electrolyser cells has been utilized for several decades. The ECSA of the electro-active species is calculated from the current density $\mathrm{Q}\left(\mathrm{C} / \mathrm{cm}^{2}\right.$ electrode $)$ obtained from the $\mathrm{CV}$ experiments, the charge required to reduce a monolayer of protons on $\mathrm{Pt} \mathrm{Gamma}=210 \mu \mathrm{C} / \mathrm{cm}^{2}$, and the Pt content or loading in the electrode. $\mathrm{L}$ is recorded in $\mathrm{g} / \mathrm{cm}^{2}$ electrode (Kinoshita K. \& Stonehart P., 1977 \& Gloagen et al., 1997).

$$
E C S A=\frac{Q_{p t}}{210, L}
$$

ECSA is only an indication of the catalyst particles that participate in the reaction medium. The fraction of the catalyst that participates in the electrode reaction is given by the ratio of the electrochemical surface area to the specific area of the catalyst. This is determined by an ex situ technique, such as XRD analysis or Brunauer-Emmett-Teller (BET) analysis. This ratio is referred to as the catalyst utilization; and the higher this value, the better is the catalyst. Figure 5 shows a CV scan for Pt.

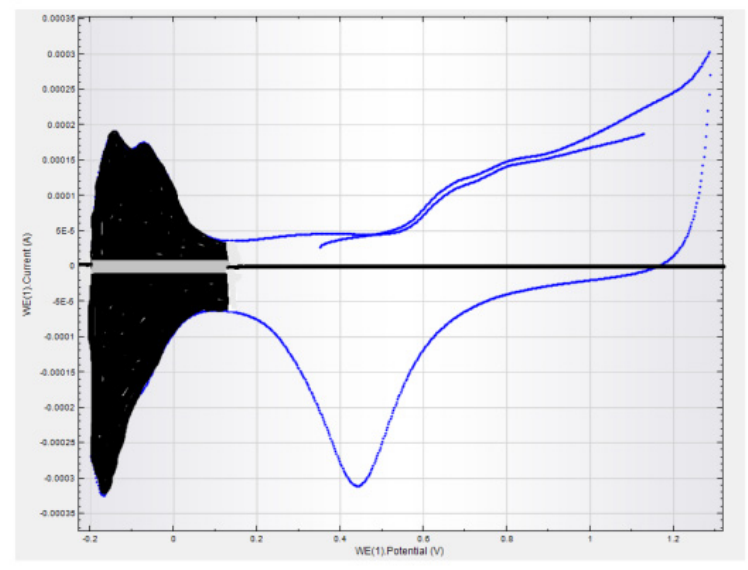

Figure 5. CV curve for a Pt catalyst. The grey areas represent the $Q$ ads and $Q$ des peak areas respectively.

This current contribution response is a non-linear response that corresponds to a hydrogen absorption reaction occurring on the electrochemically active catalyst surface. The grey areas in Figure 5 represent the $\mathrm{Q}$ adsorption $\left(\mathrm{Q}_{\mathrm{ads}}\right)$ and $\mathrm{Q}$ desorption $\left(\mathrm{Q}_{\mathrm{des}}\right)$ peak areas of the $\mathrm{Pt}$ electrolysis catalyst surface, respectively. The electrochemical active surface area can be calculated from the area under the $Q_{\text {ads }}$ and $Q_{\text {des. }}$ 
It could be noted that a highly porous, well-made MEA electrode may have an active surface area that is several orders of magnitude larger than its geometric area ( $\mathrm{O}^{\prime}$ Hayre et al., 2002). This could be expressed as the ECSA.

Half-cell experiments are convenient and relatively fast methods of analysis for the screening of various catalysts; but they are not suitable for the evaluation of PEM electrodes in-situ, since these are the conditions for an electrolytic cell setup.

\section{Kinetic measurements}

Kinetic parameters can be obtained from the steady state polarization curve also called a current-voltage graph $(\mathrm{J}-\mathrm{V})$. The J-V curve shows the voltage output as a function of current density loading in a PEM electrolyser. The performance of the characteristic J-V curve can be used to calculate the Tafel slope in the low current density (high load resistance) region, where the mass and ohmic transport effects do not interfere with the data. A typical polarization curve is shown in Figure 6.

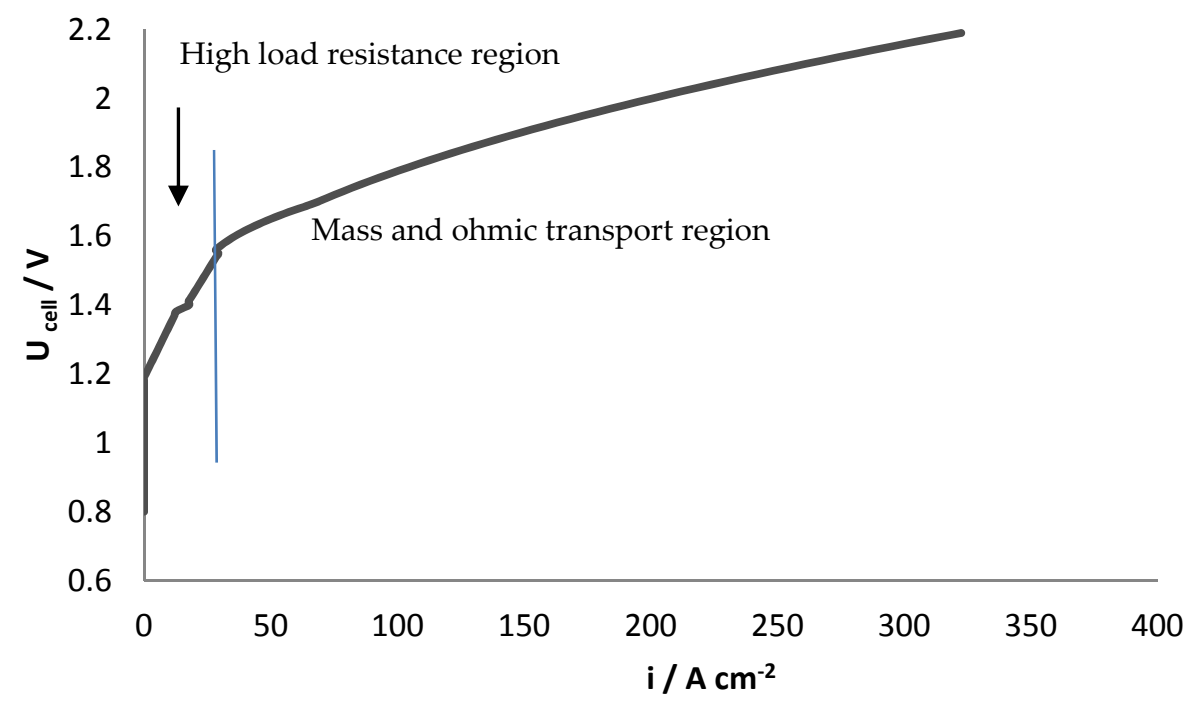

Figure 6. Typical PEM electrolyser J-V curve

By controlling the current or the potential across the electrode surface, the steady state polarization behaviour of the electrochemical reaction can be measured. The steps are performed in small increments; and the response is measured typically after 10 minutes, when the equilibrium conditions of the electrode reaction can be assumed. The J-V steadystate polarization curve includes effects of thermodynamic potentials, the overpotential due to surface reactions, ohmic losses and diffusion terms. The required potential for the electrolyzer can be expressed in the following equation (Eqn. 6). 


$$
V=E+n_{\text {ohmic }}+n_{a c t, a}+n_{a c t, c}
$$

Where $\mathrm{E}$ is the equilibrium voltage; nohmic is the ohmic potential across the PEM, nact,ai and nact,c are the activation overpotentials at the anode and cathode, respectively. The overpotential concentrations are significantly small due to gas transport limitations in the thin electrode; and these can therefore be neglected. Kinetic rate can be determined directly from the electrolysis cell by measuring the current. The overall electrochemical reaction at the anode could be expressed by the Butler-Volmer equation (Eqn. 7), if it may be assumed that there are no transport limitations.

$$
i=i_{A 0}\left[\exp \left(\frac{\aleph_{A} V_{e}-F n_{a}}{R T}\right)-\exp \left(-\frac{\left(1-\propto_{A}\right) v_{e}-F n_{A}}{R T}\right)\right]
$$

Where iA ${ }^{A}$ is the anode exchange current density $\left[\mathrm{A} \mathrm{cm}^{-2}\right] ; V_{\mathrm{e}}$ is the stoichiometric coefficient of electrons in the anode reaction; $\propto A$ is the transfer coefficient; $n_{\mathrm{A}}$ is the anode overpotential (Bockris et al., 2000). The current inputs are directly proportional to the kinetic rate of the electrochemical reaction. To determine the kinetics and the thermodynamics of electrochemical reactions in a PEM electrolysis cell can be done by means of a Tafel analysis, which is a simplified Butler-Volmer equation. The Tafel slope equation (Eqn. 8) describes the J-V steady-state polarization curve in the kinetic controlled area.

$$
\mathrm{n}^{\text {act }}=\beta \log [\mathrm{i}]-\mathrm{A}
$$

$\mathrm{n}^{\text {Act }}=$ the voltage loss $(\mathrm{mV})$ due to the slow kinetics, $I=$ current density $\left(\mathrm{mA} \mathrm{cm}^{-2}\right)$, and A and $\beta$ are the kinetic constant parameters, while $\beta$, in particular, is the Tafel slope (Eqn. 9) (Wang, 2001).

$$
\beta=2.303 \mathrm{RT} / \alpha \mathrm{F}
$$

$\alpha$ is the transfer coefficient, ranging between a value of 0 and 1 , but it is assumed that the cathode side would show a 0.5 degree of coefficiency. The Tafel slope is a graph plotted by $\mathrm{n}^{\text {act }}(\mathrm{E}-\mathrm{V})$ as a function of the log current density; and the slope of the graph can be measured in the kinetically controlled region of the J-V polarization curve. If a high Tafel slope is obtained, this could be due to mass transport or ohmic losses in the system. Typical Tafel slopes for Ir, ranging between $30-40 \mathrm{mV} \mathrm{dec}^{-1}$ at low current densities against $120 \mathrm{mV}$ $\operatorname{dec}^{-1}$ at high current densities (Andolfatto et al., (1993).

\section{Hydrogen efficiencies}

In this section, the objective of the PEM electrolyser catalyst characterization is to improve catalyst hydrogen efficiencies and to bring down the high material costs involved in these electrolytic systems. The main focus area required to bring down the material costs of PEM electrolysers could be to further develop and improve the noble metal catalysts. The following could be done to reduce the amounts of noble metals used in the PEM water electrolyser:

- Smaller amounts of PGM metals,

- Maintaining higher energy outputs with lower catalyst loadings, 
- Higher hydrogen production capacity,

- Effectively increasing the lifetime of the PEM electrolyser.

In order to facilitate these improvements in today's technologies, the system must be characterized and evaluated, in order to understand and reveal the most important limitations; and further optimization of the electrode catalysts must be carried out.

Thermodynamics could be used to calculate the hydrogen efficiencies from the overall chemical reaction, by using Faraday's law (Voigt et al., 2005). At stoichiometry, water decomposes into one part oxygen for every two parts of hydrogen. This amount of electricity (n.F.E), where $n=$ moles of the water molecule, $F=$ Faraday's constant, and $\mathrm{E}$ is the thermodynamic potential associated with the decomposition of a water molecule. This equitation is referred to as Gibbs free energy $\Delta \mathrm{Gd}$, as shown in Eqn. 10 of the water dissociation reaction:

$$
\Delta \mathrm{Gd}-\mathrm{nFE}=\mathrm{O} \text { and } \Delta \mathrm{Gd}_{\mathrm{d}}>0
$$

Where $\mathrm{n}=2$ the number of electrons exchanged during the electrochemical decomposition of water; Gibbs free energy is a function of both the operating temperature and the pressure of the electrolysis cell, and thus Eqn. 11 is:

$$
\Delta \mathrm{Gd}_{\mathrm{d}}(\mathrm{T} ; \mathrm{P})=\Delta \mathrm{H}_{\mathrm{d}}(\mathrm{T} ; \mathrm{P})-\mathrm{T} \Delta \mathrm{S}_{\mathrm{d}}(\mathrm{T} ; \mathrm{P})>0
$$

$\Delta \mathrm{H}_{\mathrm{d}}(\mathrm{T} ; \mathrm{P})$ and $\mathrm{T} \Delta \mathrm{S}_{\mathrm{d}}(\mathrm{T} ; \mathrm{P})$ are respectively the enthalpy change $\left(\mathrm{J} \mathrm{mol}^{-1}\right)$ and entropy change $(\mathrm{J}$ $\mathrm{mol}^{-1} \mathrm{~K}^{-1}$ ) associated with the decomposition of water. To be able to decompose one molecule of water, heat is required. The thermodynamic potential is defined according to Eqn. 12:

$$
E(T ; P)=\frac{\Delta G_{d}(T: P)}{n F}
$$

The thermo-voltage $\mathrm{V}$ is defined, as described in the following equation, Eqn. 13:

$$
V(T ; P)=\frac{\Delta H(T: P)}{n F}
$$

The hydrogen efficiency could be derived from Eqn. 14 where $n$ efficiency is as follows:

$$
n_{\text {efficience }}=\frac{E_{\text {waterstof }}}{E_{\text {theoreticl }}}=\frac{V_{H 2} * H}{U . I . t}
$$

$\mathrm{H}_{\mathrm{o}}=$ Energy for hydrogen fuel $=12.745 \times 10^{6} \mathrm{~J} \mathrm{~m}^{-3}$

$\mathrm{V}_{\mathrm{H} 2}=$ Volume of hydrogen produced in $\mathrm{m}^{3}$

$\mathrm{U}=$ Potential in $\mathrm{V}$

$\mathrm{I}=$ Current loading in A

$\mathrm{T}=$ time in seconds

According to literature studies, the PEM electrolyser cell potential is usually reported to be in the region of $2 \mathrm{~V}$, and the commercial type PEM electrolysers usually have an efficiency ranging from $65 \%$ to $80 \%$ (Barbir, 2005). This efficiency could increase to almost $95 \%$ at higher operating temperatures; this condition requires a lower cell voltage, which also 
lowers the current that passes through the electrolyte, while the hydrogen production rate increases. The problem could be overcome by utilizing a stack in the electrolyser setup to increase the efficiency.

\section{Concluding remarks}

This chapter discusses the difference between two electrolytic units (e.g. alkaline versus polymer electrode membrane (PEM) electrolyser units). There is a third type still under research investigation namely, the solid oxide electrolyser unit. Currently there are six major suppliers identified to produce hydrogen by an alkaline electrolytic unit and they are:

Norsk Hydro in Norway, Hydrogenics in Belguim, Iht in Switzerland, AccaGen in Switzerland, Erre Due in Italy represented by H2Indistrial in Denmark, and Uralkhimmash in Russia. In contrast to these bigger units, PEM units supplied by Proton are sized for home or small neighborhood grid systems.

This trend comes into effect because of the high capital cost associated with PEM electrolyser units, which is being pushed by expensive materials that are used to manufacture the membrane, and the costs associated with the PGM metals used as catalysts in PEM electrolyser units. This compared to the lower capital cost for the manufacturing of alkaline units. Other factors that give PEM's an advantage are that these units are safer to use when compared to alkaline units and PEM units do not utilize caustic liquids such as potassium hydroxide when compared to the solid electrolyte used in PEM units.

PEM electrolyser catalysts and MEA components can be characterized by a variety of electrochemical methods. Quick-screen cyclic voltammetry, rotating disc and linear potentiometry can be used to characterize and study the electrocatalytic behaviour. These studies can provide valuable information regarding the kinetics, the controlled potentials, and mechanisms at play during half-cell measurements of the catalysts. An electrochemically active surface area, specific activity, and electronic resistance are all needed to optimize PEM electrolysis, in order for it to operate and give optimal performance.

$\mathrm{J}-\mathrm{V}$ steady-state polarization curves can provide information regarding the open circuit voltage, thermodynamic (hydrogen efficiencies) and kinetics (Tafel slopes). Typical Tafel slopes found for Ir catalyst were between $30-40 \mathrm{mV} \mathrm{dec}^{-1}$ at low current densities against 120

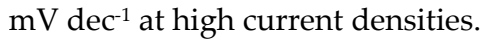

Hydrogen efficiencies are calculated based on Faraday's equations and give a good overall performance of the PEM electrolyser unit. Typical units reported give a potential output of about $2 \mathrm{~V}$ with hydrogen efficiencies ranging between $65-80 \%$. With the correct catalyst materials and electrolyser design, this efficiency can be increased to $95 \%$ at higher operating temperatures.

\section{Author details}

Shawn Gouws

Nelson Mandela Metropolitan University, South Africa 


\section{Acknowledgement}

The author wishes to thank the Nelson Mandela Metropolitan University for facilitating that this research could be conducted at an Institute; for financial funding from NRF (National Research Foundation) and HYSA (Hydrogen South Africa) who both supported this programme for a number of years.

\section{References}

Adams R. \& Shriner R.L.: (1923), Platinum oxide as a catalyst in the reduction of organic compounds. iii. Preparation and properties of the oxide of platinum obtained by the fusion of chloroplatinic acid, Journal of American Chemical Society, Vol. 45, Issue 9, ISSN 1520-5126 pp2171-2179

Andolfatto F., Durand R., Michas A., Millet P. and Stevens P., (1994), Solid Polymer Electrolyte Water Electrolysis: Electrocatalysis and Long-term Stability, International Journal of Hydrogen Energy, Vol. 19, Issue 5, pp421-427

Atlam O. \& Kolhe M. (2011), Equivalent electrical model for a proton exchange membrane (PEM) electrolyser, Energy Conservation and Management, Vol. 52, pp2952-2957

Balaji R., Senthil N., Vasudevan S., Ravichandran S., Mohan S., Sozhan G., Madhu S., Kennedy J. \& Pushpavanam S., (2011), Development and performance evaluation of Proton Exchange Membrane (PEM) based hydrogen generator for portable applications, International Journal of Hydrogen Energy, Vol. 36, pp1399-1403

Barbir F., (2005), PEM electrolysis for the production of hydrogen from renewable energy sources, Solar Energy, Vol. 78, pp661-669.

Bockris J. O'M., \& Reddy A.K.N., (2000), Modern Electrochemistry, Kluwer Academic / Plenum Publishers, New York.

Cheng J., Zhang H., Ma H., Zhong H. and Zou Y., (2009), Preparation of Ir0.4Ru0.6MoxOy for oxygen evolution by modified Adam's fusion method International Journal of Hydrogen Energy, Vol.34, pp6609-6613.

Gloaguen F., Leger J-M. and Lamy C., (1997), Electrocatalytic Oxidation of Methanol on Platinum Nanoparticles Electrodeposited onto Porous Carbon Substrates, Journal of Applied Electrochemistry, DOI:10.1023/A:1018434609543, Vol.27, pp1052 - 1060.

Hutchings R., Muller K., Kotz R. \& Stucki S., (1984), A structural investigation of stabilized oxygen evolution catalysts, Journal of material sciences, DOI:10.1007/BF00980762, Vol. 19, p3987-3994

Ivy J,; (2004), Summary of electrolytic hydrogen production, NREL/MP-560-36734, p4

Kinoshita K. \& Stonehart P., (1977), Preparation and Characterization of Highly Dispersed Electrocatalytic Materials, In. Modern Aspects of Electrochemistry, Bockris J.O.M. and Conway B.E., Eds., and Plenum Press: New York, Vol. 12, and Chapter 4, pp183-266

Kissinger P.T. \& Heineman W.R., Large-Amplitude Controlled-Potential Techniques, In. Laboratory Techniques in Electro-analytical Chemistry, Kissinger P.T. \& Heineman W.R., $2^{\text {nd }}$ Ed, Marcel Dekker, Inc, New York, ISBN,0-8247-9445-1, p81.

Kreuter W, and Hofmann H, (1998), .Electrolysis: the important energy transformer in a world of sustainable energy, International Journal Hydrogen Energy, Vol. 23, Issue 8, pp 661-666. 
Kumpulainen H., Peltonen T., Koponen U, Bergelin M., Valkiainen M. and Wasberg M., (2002) In-situ volumetric characterization of PEM Fuel Cell Catalyst layer, ESP00

Marshall A., Borresen B., Hagen G., Tsypkin M. and Tunold R., (2007), Hydrogen production by advanced proton exchange membrane (PEM) water electrolysers Reduced energy consumption by improved electrocatalysis, Energy, Vol 32, pp431- 436.

Marshall A., Borresen B., Hagen G., Tsypkin M. and Tunold R., (2004), Nanocrystaline Ir×Sn1${ }_{x} \mathrm{O}_{2}$ electrocatalysts for oxygen evolution in water electrolysis with polymer electrolyte effect of heat treatment, Journal New Material electrochemistry Systems, Vol 7, pp197-204.

Marshall A., Borresen B., Hagen G., Tsypkin M. and Tunold R., (2005), Preparation and characterization of nanocrystalline $\operatorname{Ir}_{x} \mathrm{Sn}_{1-\mathrm{x}} \mathrm{O}_{2}$ electrocatalytic powders, Material Chemical Physics, Vol 51, pp226-232

Marshall A.T., Sunde S., Tsypkin M. \& Tunold R., (2007), Performance of a PEM water electrolysis cell using IrxRuyTazO2 electrocatalysts for the oxygen evolution electrode International Journal of Hydrogen Energy, Vol. 32, pp2320-2324

Millet P., (1994), Water electrolysis using PEM technology: electrical potential distribution inside a Nafion membrane during electrolysis, Electrochim Acta, Vol. 39, Issue: 17, pp2501-2506.

Millet P., Andolfatto F. \& Durand R., (1996), Design and performance of a solid polymer electrolyte water electrolyser, International Journal of Hydrogen Energy, Vol. 21, Issue 2, pp87-93

Millet P., Ngameni R., Grigoriev S.A. \& Fateev V.N., (2011), Scientific Engineering issues related to PEM technology: Water Electrolysers, Fuel Cells and unitized Regenerative Systems, International Journal of Hydrogen Energy, Vol. 36, pp4156-4163

O'Hayre R., Lee S-J., Cha S-W. \& Prinz F. B., (2002) A sharp peak in the performance of sputtered platinum fuel cells at ultra-low platinum loading, Journal of Power Sources, Vol. 109, pp483-493.

Oberlin R. and Fisher M., (1986), Status of the membrane process for water electrolysis, In. Hydrogen energy progress VI, proceedings of the sixth world hydrogen energy conference, Veriroglu T., Getoff N. and Weinzeirl P., Oxford, Pergamon Press, pp 333-340.

PSO-F\&U, (2008), Pre-Investigation of Water electrolysis, NEI-DK-5057

Qi Z., (2008) Electrochemical methods for catalyst activity evaluation, In., PEM Fuel cell electrocatalysts and catalyst layers, Zhang, J, Springer, ISBN 978-1-84800-935-6, Spain

Rasten E., Hagen G. and Tunold R., (2003), Electrocatalysis in water electrolysis with solid polymer electrolytes, Electrochim Acta, Vol. 48, pp3945-3952

Song S, Zhang H., Ma X., Shao Z., Baker R.T., Yi B., (2008), Electrochemical investigation of electrocatalysts for the oxygen evolution reaction in PEM water electrolysers, International Journal of Hydrogen Energy, Vol. 33, pp 4955-4961.

Trasatti S. (1991) Physical electrochemistry of ceramic oxides, Electrochim Acta, Vol.36, pp 225-241

Tseung A.C.C., \& Jasem S., (1977) Oxygen evolution on semiconducting oxides, Electrochim Acta, Vol. 22, pp31-34

Van Ruijven B.J., (2007), The potential role of hydrogen in energy systems with and without climate policy, International Journal of Hydrogen Energy, Vol. 32, Issue 12 pp 1655-1675

Wang X., Hsing I.M. and Yue P.L. (2001), Electrochemical characterization of binary carbon supported electrode in polymer electrolyte fuel cells, Power Sources, Vol.96, pp282-287

Zoulias E.,Varkaraki E., Lymberopoulos N., Chritodoulou C.N. \& Karagiorgis G.N., (2004) A review on water electrolysis, TCJST, Vol. 4, Issue 2, pp 41-71 